\title{
16S rRNA Phylogenetic Analysis of Heavy Metal Tolerant Plant Growth Promoting Rhizobacteria
}

\author{
Shuchita Verma*† and Baljeet Singh Saharan** \\ *Department of Microbiology, Microbial Resource Technology Laboratory, Kurukshetra University, Kurukshetra, \\ Haryana-136119, India \\ **Department of Microbiology, CCS Haryana Agricultural University, Hisar-125004, India \\ $†$ Corresponding author: Shuchita Verma; shuchitaverma86@gmail.com
}

Nat. Env. \& Poll. Tech.

Website: www.neptjournal.com

Received: 11-12-2019

Revised: 21-12-2019

Accepted: 03-01-2020

Key Words:

PGPR

16S rRNA sequence

Pseudomonas fluorescence

Rhizosphere

\begin{abstract}
The present study was aimed to characterize the bacterial isolate $\mathrm{DDI}(\mathrm{I}) 1$ isolated from the rhizospheric soil of Ocimum grown in New Delhi (India). The isolate exhibited multiple plant growth promoting activities namely ammonia production, production of phytohormones, hydrogen cyanide, solubilization of minerals, tolerance against heavy metals, etc. The isolate was morphologically and biochemically characterized and it was found that $\mathrm{DDI}(\mathrm{I}) 1$ belongs to genus Pseudomonas. Further, 16S rRNA sequencing revealed that the isolate shared $99 \%$ homology with Pseudomonas fluorescens.
\end{abstract}

\section{INTRODUCTION}

The rhizosphere is the region around the roots of plants where the nutrient availability is very high due to the release of plant photosynthates from the roots (Lynch 1991). This region is actively colonized by the bacterial community including beneficial bacteria known as PGPR, i.e. plant growth promoting rhizobacteria. PGPR promote the plant growth in different ways such as suppression of plant pathogens and production of useful compounds helping in increased crop yield. Due to these bacteria, we can reduce the use of chemical fertilizers (Saharan \& Nehra 2011, Glick 2012). These are an eco-friendly way for sustainable agriculture and do not pose any threat to human and animal health (Saharan \& Verma 2015).

Few examples of PGPR are B. licheniformis CECT5106, B. pumilus CECT5105, Bacillus subtilis A13, Enterobacter cloacae UW4 \& CAL2, P. fluorescens Pf-5, P. fluorescens 2-79, P. fluorescens CHA0, Pseudomonas putida GR12-2 (Turner \& Backman 1991, Jacobson et al. 1994, Shah et al. 1998, Li et al. 2000, Wang et al. 2000, Penrose \& Glick 2001, Probanza et al. 2002). One of the most promising candidates as PGPR is Pseudomonas fluorescens. Pseudomonas and Bacillus confer plant growth enhancement and control of diseases against phytopathogens (Hamid \& Ahmad 2010).
Pseudomonas fluorescence inoculant stimulated chickpea growth and yield (Rokhzadi et al. 2008). A total of 140 PGPR strains of Pseudomonas were obtained from potatoes rhizosphere at Dehradun Valley, India (Deshwal et al. 2013). About 30 PGPR strains belonging to fluorescent Pseudomonas with PGP activities were isolated from the rhizosphere of rice and characterized by PCR-RAPD analysis (Reddy \& Reddy 2009). The present study was aimed to characterize the isolate DDI(I)1 due to its multiple plant growth promoting traits it possesses.

\section{MATERIALS AND METHODS}

\section{Collection of Soil Samples, Isolation and Screening for PGP Traits}

Soil samples were collected from the rhizospheric soil of Ocimum sp. plants from different localities of Kurukshetra, Delhi and Haridwar. The intact soil of the roots was collected carefully in sterile plastic bags and stored at $4{ }^{\circ} \mathrm{C}$ in the laboratory until their further use. The isolate was obtained from the rhizospheric soil of Ocimum grown in Delhi and further screened for various PGP traits. The isolate was found to possess multiple plant growth promotion activities such as solubilization of phosphorus, IAA production, $\mathrm{HCN}$ production, siderophore production, tolerance to heavy metals, etc. 
These numerous activities render it a potential candidate for sustainable agriculture so the present study was undertaken to characterize this isolate DDI(I)1.

\section{Morphological and Phenotypic Characterization}

Selected isolates were examined for the colony morphology. Different morphological characteristics such as colony size, colour, shape, margin, pigmentation, elevation, etc. were recorded for the chosen PGPR isolates. Gram staining procedure was also performed according to the Bergy's Manual (Holt 1994).

\section{Biochemical Characterization}

The biochemical characterization of selected PGPR isolates was done according to the methods outlined by Cappuccino \& Sherman (2010). Various methods such as IMViC test, catalase, gelatin liquefaction, oxidase, hydrogen sulfide production, etc. were performed.

\section{Molecular Characterization}

DNA extraction (Biopure ${ }^{\mathrm{TM}}$ Kits): DNA was isolated from the bacterial sample by using Biopure kits for genomic DNA isolation. 16S rRNA gene was amplified using PCR by extracting DNA from a bacterial isolate. The primers used for the amplification of 16S rDNA gene were 16SF Universal 5'-AGAGTTTGA TCCTGGCTCAG-3' and 16SR Universal 3'-ACGGCTACCTTG TTACGA CTT-5'.

Amplification of 16S rDNA gene: PCR condition: Initial denaturation was done at $94^{\circ} \mathrm{C}$ for $5 \mathrm{~min}$; denaturation (35cycles) at $94^{\circ} \mathrm{C}$ for $60 \mathrm{sec}$, annealing at $53^{\circ} \mathrm{C}$ for $45 \mathrm{sec}$; extension at $72^{\circ} \mathrm{C}$ for $90 \mathrm{sec}$ and then the final extension at $72^{\circ} \mathrm{C}$ for $10 \mathrm{~min}$. The amplified PCR products were electrophoresed by using 1\% Agarose gel in TAE buffer and visualized by staining with ethidium bromide. PCR product was then purified by washing with sodium acetate and $70 \%$ of ethanol and eluted from the gel. Forward and reverse sequencing reactions of PCR amplicon were carried out on the ABI 3730XL sequencer to obtain the sequence. The assembled DNA sequence was then submitted to NCBI and phylogenetic tree was prepared.

\section{RESULTS AND DISCUSSION}

\section{Morphological and Phenotypic Characterization}

Isolate DDI(I)1 showed yellowish-green, small, round and raised colonies (Table 1). The isolate is a Gram negative, rod shaped bacterium.

\section{Biochemical Characterization}

The isolate showed a positive test for citrate utilization, oxidase, nitrate reduction, gelatin liquefaction, glucose fermentation and negative test for indole, methyl red, Vogues Prauskeur reaction and hydrogen sulfide (Table 2). Based on the morphological, phenotypic and biochemical characterization, the isolate DDI(I)1 belongs to Pseudomonas genus.

\section{Molecular Characterization and Phylogeny}

16S rDNA sequencing of PGPR isolate DDI(I)1: The molecular characterization of the isolate was done by $16 \mathrm{~S}$ rRNA Gene Sequence Analysis. The 16S rDNA sequencing

Table 1: Morphological and phenotypic characterization of DDI(I)1.

\begin{tabular}{|llll|}
\hline Characteristics & Reaction & Characteristics & Reaction \\
\hline Colour & Yellowish green & Odour & None \\
Size & Small & Pigmentation & Yellowish green \\
Shape & Round & Surface & Smooth \\
Elevation & Raised & Gram staining & -ve \\
Margin & Irregular & Shape & Rods \\
\hline
\end{tabular}

Table 2: Biochemical characterization of DDI(I)1.

\begin{tabular}{|llll|}
\hline Biochemical test & Reaction & Biochemical test & Reaction \\
\hline Indole & - & Oxidase & + \\
Methyl red & - & $\mathrm{H}_{2} \mathrm{~S}$ & - \\
$\mathrm{VP}$ & - & Nitrate reduction & + \\
Citrate & + & Gelatin liquefaction & + \\
Catalase & + & Glucose fermentation & + \\
\hline
\end{tabular}


was performed. Selected bacterial $16 \mathrm{~S}$ rDNA was amplified in full length by PCR using primers, 16SF Universal (AGA GTT TGA TCC TGG CTC AG) and 16SR Universal (ACG GCT ACC TTG TTA CGA CTT). Based on 16S rDNA sequencing data, the isolate DDI(I)1 showed 99\% homology with Pseudomonas fluorescens strain CB32.

To evaluate the phylogenetic analysis of 16S rDNA sequence, the resulting sequence was compared with the known sequences using the BLAST function of GeneBank in the National Centre Biotechnology information (http://www.ncbi. nlm.nih.gov). Multiple sequence alignments and consensus sequences were computed using the program CLUSTAL W programmed at European Bioinformatics (EBI) site (http:// www.ebi.eic.uk/clustalw) and the phylogenetic tree was constructed using MEGA 5.05 software (Fig. 1).

\section{Sequence}

> GGAATCTGCCTGGATAGTGGGGGATAACGTTCGGAAACGAACGCTAATACCGCATACGTCCTACGGGAGAAAGCAGGGGACCTTCGGGCCTTGCGCTATCAGATGAGCCTAGGTCGGATTAGCTAGTTGGTGAGGTAATGGCTCACCAAGGCGACGATCCGTAACTGGTCTGAGAGGATGATCAGTCACACTGGAACTGAGACACGGTCCAGACTCCTACGGGAGGCAGCAGTGGGGAATATTGGACAATGGGCGAAAGCCTGATCCAGCCATGCCGCGTGTGTGAAGAAGGTCTTCGGATTGTAAAGCACTTTAAGTTGGGAGGAAGGGCAGTTACCTAATACGTAATTGTTTTGACGTTACCGACAGAATAAGCACCGGCTAACTCTGTGCCAGCAGCCGCGGTAATACAGAGGGTGCAAGCGTTAATCGGAATTACTGGGCGTAAAGCGCGCGTAG-
GTGGTTCGTTAAGTTGGATGTGAAATCCCCGGGCTCAACCTGGGAACTGCATTCAAAACTGTCGAGCTAGAGTATGGTAGAGGGTGGTGGAATTTCCTGTGTAGCGGTGAAATGCGTAGATATAGGAAGGAACACCAGTGGCGAAGGCGACCACCTGGACTGATACTGACACTGAGGTGCGAAAGCGTGGGGAGCAAACAGGATTAGATACCCTGGTAGTCCACGCCGTAAACGATGTCAACTAGCCGTTGGGAGCCTTGAGCTCTTAGTGGCGCAGCTAACGCATTAAGTTGACCGCCTGGGGAGTACGGCCGCAAGGTTAAAACTCAAATGAATTGACGGGGGCCCGCACAAGCGGTGGAGCATGTGGTTTAATTCGAAGCAACGCGAAGAACCTTACCAGGCCTTGACATCCAATGAACTTTCCAGAGATGGATTGGTGCCTTCGGGAGCATTGAGACAGGTGCTGCATGGCTGTCGTCAGCTCGTGTCGTGAGATGTTGGGTTAAGTCCCGTAACGAGCGCAACCCTTGTCCTTAGTTACCAGCACGTTATGGTGGGCACTCTAAGGAGACTGCCGGTGACAAACCGGAGGAAGGTGGGGATGACGTCAAGTCATCATGGCCCTTACGGCCTGGGCTACACACGTGCTACAATGGTCGGTACAGAGGGT TGCCAAGCCG

The given sequence was identified as Pseudomonas fluorescens strain 16S ribosomal RNA gene, partial sequence length: 1423

Score: 2109 bits (1142) Identities: 1142/1142(100\%) Strand: Plus/Plus

\section{Phylogenetic analysis}

The phylogenetic analysis revealed that our isolate DDI(I)1 showed 99\% homology with Pseudomonas fluorescens CB32. In a similar study, a psychrotolerant PGPR strain

\section{Phylogenetic Tree:}

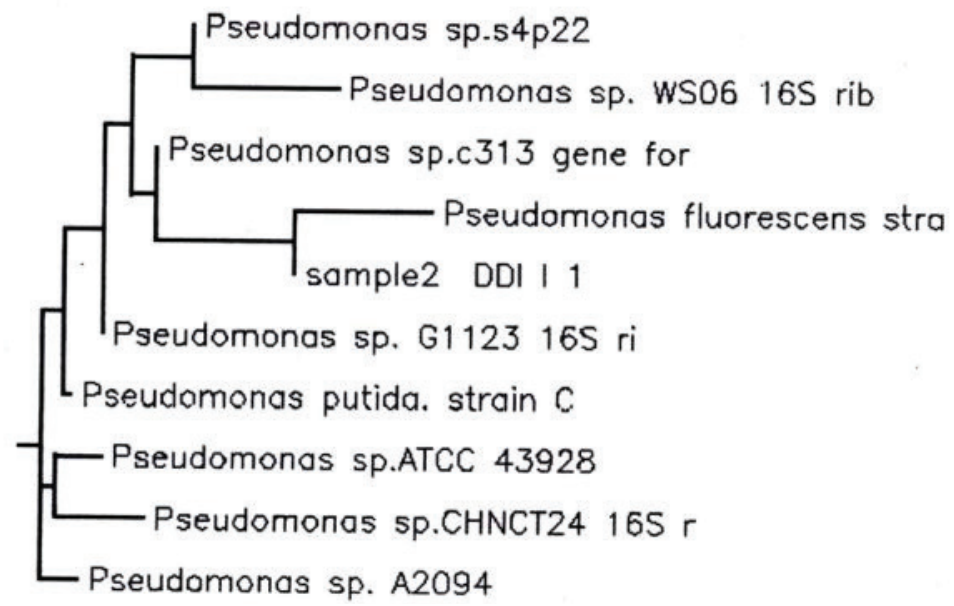

Fig. 1: Phylogenetic tree of DDI(I)1 based on $16 \mathrm{~S}$ rDNA gene sequences. 
PGERs17 was isolated from north-western Indian Himalayas and characterized the isolate which showed maximum homology (99\%) with Pseudomonas sp. The phylogenetic tree revealed the close association of the isolate with Pseudomonas vancouverensis (ATCC 700688), Pseudomonas alcaligenes (ATCC 14909), Pseudomonas tolaasii (ATCC 33618) and Pseudomonas agarici (ATCC 25941) (Mishra et al. 2008). Isolate CV6 was characterized as Pseudomonas fluorescens as the potent biocontrol agent against Phytophthora drechsleri (Maleki et al. 2010). In another investigation, 10 bacterial isolates (AW1 to AW10) were selected from the wheat rhizosphere. Out of these, AW8 showed 98\% homology with Pseudomonas aeruginosa (Rana et al. 2011).

\section{CONCLUSION}

This present study suggested that the $P$. fluorescens DDI(I) 1 can exhibit multiple plant growth promoting traits such as the production of ammonia, hydrogen cyanide production, siderophore production, solubilization of phosphorus, etc. The $P$. fluorescens DDI(I)1 bacterial strain was also found to exhibit heavy metal tolerance against copper, lead, nickel and zinc. Due to the multiple PGP traits exhibited by rhizospheric isolate, it may be useful as a bio-inoculant in sustainable agriculture.

\section{REFERENCES}

Cappuccino, J.C. and Sherman, N. 2010. In: Microbiology: A Laboratory Manual, $10^{\text {th }}$ Edn., New York. Benjamin/Cummings Pub. Co., pp. 125-179.

Deshwal, V.K., Singh, S.B., Chaubey, A. and Kumar, P. 2013. Isolation and characterization of Pseudomonas strains from potatoes rhizosphere at Dehradun valley, India. Int. J. Basic Appl. Sci., 2(2): 53-55.

Glick, B.R. 2012. Plant Growth-Promoting Bacteria: Mechanisms and Applications. Hindawi Publishing Corporation, Scientifica.

Hamid, A. and Ahmad, G. 2010. The effect of seed inoculation (Pseudomonas putida + Bacillus lentus) and different levels of fertilizer on yield and yield components of wheat (Tritium aestivum L.) activities. World Acad. Sci. Eng. Technol., 4: 1369-1373.

Holt, J.G., Krieg, N.R., Sneath, P.H.A., Staley, J.T. and Williams, S.T. 1994. Bergey's Manual of Determinative Bacteriology (ed. 9th). Williams and Wilkins Publishers, Baltimore Maryland, USA., pp. 786-788.

Jacobson, C.B., Pasternak, J.J. and Glick, B.R. 1994. Partial purification and characterization of 1-aminocyclopropane-1-carboxylate deaminase from PGPR, Pseudomonas putida GR12-2. Can. J. Microbiol., 40:
1019-1025.

Li, J., Daniel, H., Charles, T.C. and Glick, B.R. 2000. An ACC deaminase minus mutant of Enterobacter cloacae UW4 no longer promotes root elongation. Curr. Microbiol., 41: 101-105.

Lynch, J.M. and Whipps, J.M. 1991. Substrate flow in the rhizosphere. In: Keister DL, Cregan PB. (Eds.), The rhizosphere and plant growth. Beltsville Symposia in Agric. Res. vol 14. Springer, Dordrecht, The Netherlands.

Maleki, M., Mostafee, S., Mohammad, L. and Farzenah, M. 2010. Characterization of Pseudomonas fluorescence strains CV-6 isolated from cucumber rhizosphere in varamin as a potential biocontrol agent. Aust. J. Crop Sci., 4(9): 676-683.

Mishra, P.K., Mishra, S., Selvakumar, G., Bisht, S.C., Bisht, J.K., Kundu, S. and Gupta, H.S. 2008. Characterisation of a psychrotolerant plant growth promoting Pseudomonas sp. strain PGERs17 (MTCC 9000) isolated from north western Indian Himalayas. Ann. Microbiol., 58(4): 561-568.

Penrose, D.M. and Glick, B.R. 2001. Levels of ACC and related compounds in exudates and extracts of canola seeds treated with ACC deaminase-containing plant growth promoting bacteria. Can. J. Microbiol., 47: 368-372.

Probanza, A., Lucas Garcia, J.A., Palomino, M.R., Ramos, B. and Gutierrez Manero, F.J. 2002. Pinus pinea L. seedling growth and bacterial rhizosphere structure after inoculation with PGPR Bacillus (B. licheniformis CECT 5106 and B. pumilus CECT 5105). Appl. Soil Ecol., 20: 75-84.

Rana, A., Saharan, B., Joshi, M., Prasanna, R., Kumar, K. and Nain, L. 2011. Identification of multi-trait PGPR isolates and evaluating their potential as inoculants for wheat. Ann. Microbiol., 61: 893-900.

Reddy, P.K. and Reddy, M.S. 2009. Biochemical and PCR-RAPD characterization of Pseudomonas fluorescens produced antifungal compounds inhibit the rice fungal pathogens in vitro. J. Pure Appl. Microbiol., 3(1): 1-4.

Rokhzadi, A., Asharzadeh, A., Darvish, F., Nour-Mohammadi, G. and Majidi, E. 2008. Influence of plant growth promoting rhizobacteria on dry matter accumulation of Chickpea (Cicer arietinum $\mathrm{L}$ ) under field conditions. J. Agric. Environ. Sci., 3(2): 253-257.

Saharan, B.S. and Nehra, V. 2011. Plant growth promoting rhizobacteria: A critical review. Life Sci. Med. Res., 21: 1-30.

Saharan, B.S. and Verma, S. 2015. Evaluation of rhizospheric bacteria from Ocimum sp. as potential PGPR. J. Microb. Biochem. Technol., 7(2): 088-095.

Shah, S., Li, J., Moffatt, B.A. and Glick, B.R. 1998. Isolation and characterization of ACC deaminase genes from two different plant growth-promoting rhizobacteria. Can. J. Microbiol., 44: 833-843.

Turner, J.T. and Backman, P.A. 1991. Factors relating to peanut yield increases after seed treatment with Bacillus subtilis. Plant Dis., 75: 347-353.

Wang, C., Knill, E., Glick, B.R. and Defago, G. 2000. Effect of transferring 1- aminocyclopropane-1-carboxylic acid (ACC) deaminase genes into Pseudomonas fluorescens strain $\mathrm{CHAO}$ and its gacA derivative CHA96 on their growth-promoting and disease-suppressive capacities. Can. J. Microbiol., 46: 898-907. 